\title{
Comportamento de mudas de nim à salinidade da água em solo não salino com biofertilizante
}

\author{
Járisson C. Nunes ${ }^{1}$, Lourival F. Cavalcante ${ }^{2}$, Antonio J. de Lima Neto ${ }^{3}$, \\ Alex M. Rebequi ${ }^{4}$, Belísia L. M. T. Diniz ${ }^{5} \&$ Hans R. Gheyi ${ }^{6}$
}

\begin{abstract}
RESU M 0
U m experimento foi desenvolvido em ambiente telado do Departamento de Solos e Engenharia Rural da U niversidade Federal da Paraíba, Areia, PB, no período de janeiro a abril de 2010. 0 substrato constou de material de um N eossolo Q uartzarênico não salino, coletado na camada de $0-20 \mathrm{~cm}$. Os tratamentos foram dispostos em delineamento inteiramente casualizado em esquema fatorial $5 \times 2$, referente aos níveis de salinidade da água de irrigação de 0,$5 ; 1,0 ; 2,0 ; 3,0$ e 4,0 dS m-1 , no solo sem e com biofertilizante comum, aplicado ao solo uma única vez, após diluição em água, na proporção de 1:1, um dia antes da semeadura, em volume correspondente a $10 \%$ do volume do substrato. Aos 86 dias após a emergência das plântulas normais avaliaram-se o crescimento em altura e o comprimento da raiz, diâmetro do caule e da raiz, número de folhas e a massa seca das raízes e parte aérea das plantas. 0 conteúdo salino da água de irrigação elevou a condição salina do substrato ao ponto de comprometer o crescimento em altura e diâmetro do caule, número de folhas, diâmetro e comprimento da raiz principal, massa seca das raízes e parte aérea (folhas + caule) do nim mas com declínios menos pronunciados nos tratamentos com biofertilizante bovino.
\end{abstract}

Palavras-chave: Azadirachta indica, estresse salino, insumo orgânico

\section{Behavior of neem seedlings under water salinity in a non-saline soil with biofertilizer application}

\begin{abstract}
A B STRACT
An experiment was carried out in greenhouse during the period January to April 2010, at Center of Agricultural Sciences of the Federal U niversity of Paraiba, in Areia, Paraiba State, Brazil, in order to evaluate the effects of saline water and bovine biofertilizer on the seedling grow th of Indian neem. The substrate was material of a non-saline soil collected in depth of $0-20 \mathrm{~cm}$. The treatments were arranged in a completely randomized design using a $5 \times 2$ factorial, referring to salinity levels of irrigation water of $0.5,1.0,2.0,3.0$ and $4.0 \mathrm{dS} \mathrm{m}^{-1}$, with and without bovine biofertilizer applied to the soil only once after dilution with water (1:1), a day before sowing, in volume corresponding to $10 \%$ of the substrate. At 86 days after emergence of seedlings the plant growth in height and principal root length, diameter of stem and root, leaf number and dry mass of roots and shoots of plants were evaluated. The salinity of irrigation water increased the salinity levels in the substrate inhibiting the growth in height, stem diameter, leaf emission by plants, diameter and length of principal root and the dry matter production of roots and aerial parts (leaves + stem) of neem, but with less pronounced decrease in plants under the treatments with bovine biofertilizer.
\end{abstract}

Key words: Azadirachta indica, saline stress, organic manure

\footnotetext{
${ }^{1}$ M estrando em Ciência do Solo do PPGCS/CCA/ U FPB. Cidade Universitária, CEP 58397000, Areia, PB. Fone: (83) 3362-2300, Ramal 3297. E-mail: jarissonagro@hotmail.com

2 Departamento de Solos e Engenharia Rural, CCA/U FPB, pesquisador do INCTSal. Cidade Universitária, CEP 58397000, Areia, PB. Fone: (83) 3362-2300, ramal 3297. E-mail: Iofeca@cca.ufpb.br

${ }^{3}$ FCAV/U N ESP, D epto. de Solos e Adubos, Rodov. Prof. Paulo D onato Castellane, s/n, CEP 14884-900, Jaboticabal, SP. E-mail: limanetoagro@ hotmail.com ${ }^{4}$ D outorando em Ciência do Solo do PPGCS/CCA/UFPB. Fone: (83) 3362-2300. E-mail: alexrebequi@hotmail.com

${ }^{5}$ D epartamento de Agropecuária do CCHSA/U FPB. Cidade U niversitária, CEP 58220-000, Bananeiras, PB. Fone: (83) 3367-1200, Ramal 2246. E-mail: belisialucia@cchsa.ufpb.br

${ }^{6}$ NEAS/UFRB, CEP 44380-000, Cruz das Almas, BA. E-mail: hans@pq.cnpq.br
} 


\section{INTRODUÇÃO}

O nim (Azadirachta indica A. Juss) é uma planta exótica, rústica, com porte de árvore, pertencente à família Meliaceae, originária da Ásia, distribuída nas áreas tropicais e subtropicais da África, Austrália e Américas, inclusive no Brasil (Azevedo et al., 2010). Pela sua rusticidade se desenvolve em solos fisicamente degradados, exige $\mathrm{pH}$ entre 6 e 7 mas também tolera amplitudes dessa variável de 3 a 9, cresce e produz em regiões com pluviosidades oscilando de 400 a $800 \mathrm{~mm}$ e suporta longos períodos de estiagem (Freire et al., 2010).

Dentre outras utilidades do nim se destacam a ação fitoprotetora como a função bioinseticida e biofungicida dos extratos obtidos das folhas e sementes (Mourão et al., 2004), dureza e resistência da madeira às térmitas, riqueza do cerne, em tanino e sais inorgânicos de cálcio, potássio e ferro, o que lhe garante longa duração.

Também é empregada como combustível na fabricação de carvão vegetal para aquecimento de caldeiras e cerâmicas. Além dessas funções é utilizada na preparação de vigas para escoramento na construção civil, estacas e mourões para cercas, postes para rede elétrica e em marcenarias, na fabricação de móveis (Chaturvedi et al., 2004).

As características de rusticidade e utilização das folhas, sementes e madeira do nim, constituem critérios para o uso em programas de reflorestamento e recuperação de áreas degradadas fisicamente nas regiões costeira e semiárida do Nordeste, inclusive no estado da Paraíba (Neves, 2004). Entretanto, no que se refere ao crescimento inicial e ao seu estabelecimento em ambientes salinos, as informações ainda são escassas na literatura. Neste sentido, Gurumurthy et al. (2007), Cha-Um \& Kirdmanee (2008) e Freire et al. (2010) constataram que, durante a formação de mudas e até o primeiro ano, o nim se comporta como moderadamente tolerante e moderadamente sensível à salinidade.

A expansão das áreas comprometidas por sais nos perímetros irrigados do Nordeste brasileiro, constitui transtornos econômicos e sociais à região semiárida onde o sistema produtivo depende da irrigação e a cada dia novas áreas de produção são instaladas para atender à crescente demanda alimentar (Medeiros et al., 2010). Esta inconveniência pode transformar terras produtivas em devolutas, motivo pelo qual exige a adoção de tecnologias que minimizem a salinização dos solos com o manejo da água ou que permitam produzir em áreas comprometidas por sais sem grandes perdas de rendimento e qualidade da produção.

Uma das possibilidades de reinserir as áreas abandonadas ou com elevada salinidade ao sistema produtivo, conforme Freire et al. (2010) é a utilização de plantas destinadas à produção de alimentos, pecuária ou para reflorestamento, que produzam com viabilidade econômica em áreas sem função agrícola pela salinidade ou sodicidade. Neste sentido, ao considerar as utilidades e o caráter rústico do nim ao sobreviver e produzir em áreas degradadas fisicamente, bem como o crescimento em solo fortemente salino $\left(\right.$ CEes $\left.=11 \mathrm{dS} \mathrm{m}^{-1}\right)$ como apresentado por Silva et al. (2010) sua inclusão nas áreas afetadas por sais pode ser promissora.
Tal possibilidade, associada ao emprego de resíduos de origem animal ou vegetal, ricos em ácidos orgânicos (Liang et al., 2005; Silva Júnior et al., 2009) e que mitiguem os efeitos danosos da salinidade da água ou do solo às plantas, também deve ser recomendada em solos salinizados. Assim, Silva et al. (2008), Nunes et al. (2009) e Asik et al. (2009) irrigaram plantas de goiabeira (Psidium guajava), noni (Morinda citrifolia) e trigo (Triticum duram Salihli) com águas de salinidade crescente até $8 \mathrm{dS} \mathrm{m}^{-1}$ (goiabeira), até $4 \mathrm{dS} \mathrm{m}^{-1}$ (noni) e trigo até $3 \mathrm{dS} \mathrm{m}^{-1}$, e as plantas, em todas as situações, cresceram mais nos substratos com esterco de bovino aplicado ao solo nas formas sólida e líquida.

Com base no exposto, objetivou-se avaliar o crescimento inicial de mudas de nim, em solo não salino, irrigado com águas salinas e com biofertilizante bovino.

\section{Material E MÉTODOS}

O experimento foi desenvolvido entre os meses de janeiro a abril de 2009, em ambiente telado do Departamento de Solos e Engenharia Rural da Universidade Federal da Paraíba, Areia, $\mathrm{PB}$, com variação de temperatura de 29 a $38^{\circ} \mathrm{C}$ e de umidade relativa do ar 50 a $75 \%$, respectivamente. O município está inserido na microrregião do Brejo paraibano e possui as coordenadas geográficas $6^{\circ} 58^{\prime} 12^{\prime \prime}$ de latitude Sul, 35 $35^{\circ}$ ' 15 ", de longitude a Oeste de Greenwich com $619 \mathrm{~m}$ de altitude.

O substrato foi um Neossolo Quartzarênico não salino, coletado nos primeiros $20 \mathrm{~cm}$ de profundidade, caracterizado fisicamente pela densidade do solo e das partículas, porosidade total, teores de areia, silte e argila utilizando-se as metodologias recomendadas por EMBRAPA (1997) e quimicamente quanto à salinidade, através dos valores de condutividade elétrica, $\mathrm{pH}$, conteúdos de $\mathrm{Ca}^{2+}, \mathrm{Mg}^{2+}, \mathrm{Na}^{+}, \mathrm{K}^{+}, \mathrm{Cl}^{-}, \mathrm{CO}_{3}{ }^{2-}, \mathrm{HCO}_{3}{ }^{-} \mathrm{e} \mathrm{SO}_{4}{ }^{2-}$, do extrato de saturação (Richards, 1954), conforme a Tabela 1 e de fertilidade para obtenção de sódio e dos componentes da capacidade de troca catiônica, para cálculo da percentagem de sódio trocável (PST).

Os tratamentos foram dispostos em delineamento inteiramente casualizado, em seis repetições, usando-se o esquema fatorial 5 x 2, referente aos níveis de salinidade da água de irrigação 0,$5 ; 1,0 ; 2,0 ; 3,0$ e $4,0 \mathrm{dS} \mathrm{m^{-1 }}$, preparados a partir da diluição de uma água fortemente salina $\left(12,8 \mathrm{dS} \mathrm{m}^{-1}\right)$

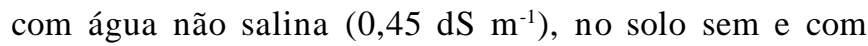
biofertilizante comum, aplicado ao solo uma única vez, um dia antes da semeadura na proporção em água de 1:1 e no volume correspondente a $10 \%$ volume do substrato $(300 \mathrm{~mL})$.

O biofertilizante comum (água + esterco fresco de bovino) foi obtido sob fermentação anaeróbica. Para se produzir $200 \mathrm{~L}$ de biofertilizante comum ou puro, foram adicionados $100 \mathrm{~L} \mathrm{de}$ esterco bovino fresco e $100 \mathrm{~L}$ de água em um recipiente de 240 $\mathrm{L}$, mantendo-o hermeticamente fechado durante trinta dias (Rebequi et al., 2009). O biofertilizante bovino na proporção em água de 1:1 foi analisado como se fosse água para irrigação, quanto à sua composição química (Tabela 2), conforme a metodologia sugerida por Richards (1954) e EMBRAPA (1997). 
Tabela 1. Atributos físicos e químicos do extrato de saturação do solo

\begin{tabular}{|c|c|}
\hline Atributos físicos & Valores \\
\hline $\begin{array}{l}\text { Densidade do solo }\left(\mathrm{kg} \mathrm{dm}^{-3}\right) \\
\text { Densidade de partículas }\left(\mathrm{kg} \mathrm{dm}^{-3}\right) \\
\text { Porosidade Total }\left(\mathrm{m}^{3} \mathrm{~m}^{-3}\right) \\
\text { Areia }\left(\mathrm{g} \mathrm{kg}^{-1}\right) \\
\text { Silte }\left(\mathrm{g} \mathrm{kg}^{-1}\right) \\
\text { Argila }\left(\mathrm{g} \mathrm{kg}^{-1}\right) \\
\text { ADA }\left(\mathrm{g} \mathrm{kg}^{-1}\right) \\
\text { GF }(\%) \\
\text { ID }(\%) \\
\text { Ucc }\left(\mathrm{g} \mathrm{kg}^{-1}\right)-10 \mathrm{kPa} \\
\text { Upmp }\left(\mathrm{g} \mathrm{kg}^{-1}\right)-150 \mathrm{kPa} \\
\text { ADI }\left(\mathrm{g} \mathrm{kg}^{-1}\right)\end{array}$ & $\begin{array}{r}1,54 \\
2,67 \\
0,52 \\
854,00 \\
71,00 \\
85,00 \\
13,00 \\
84,70 \\
15,30 \\
10,32 \\
5,29 \\
5,03\end{array}$ \\
\hline \multicolumn{2}{|l|}{ Atributos químicos } \\
\hline $\begin{array}{l}\text { CEes a } 25^{\circ} \mathrm{C}\left(\mathrm{dS} \mathrm{m} \mathrm{m}^{-1}\right) \\
\mathrm{pH} \\
\mathrm{Ca}^{2+}\left(\mathrm{mmol}_{\mathrm{c}} \mathrm{L}^{-1}\right) \\
\mathrm{Mg}^{2+}\left(\mathrm{mmol}_{\mathrm{c}} \mathrm{L}^{-1}\right) \\
\mathrm{Na}^{+}\left(\mathrm{mmol}_{\mathrm{c}} \mathrm{L}^{-1}\right) \\
\mathrm{K}^{+}\left(\mathrm{mmol}_{\mathrm{c}} \mathrm{L}^{-1}\right) \\
\mathrm{Cl}^{-}\left(\mathrm{mmol}_{\mathrm{c}} \mathrm{L}^{-1}\right) \\
\mathrm{CO}_{3}^{2-}\left(\mathrm{mmol}_{\mathrm{c}} \mathrm{L}^{-1}\right) \\
\mathrm{HCO}_{3}^{-}\left(\mathrm{mmol}_{\mathrm{c}} \mathrm{L}^{-1}\right) \\
\mathrm{SO}_{4}^{2-}\left(\mathrm{mmol}_{\mathrm{c}} \mathrm{L}^{-1}\right) \\
\text { RAS }\left(\mathrm{mmol} \mathrm{L}^{-1}\right)^{1 / 2} \\
\text { PST }(\%)\end{array}$ & $\begin{array}{r}0,78 \\
6,60 \\
1,70 \\
0,60 \\
0,26 \\
112,00 \\
4,17 \\
\text { Ausente } \\
1,50 \\
2,15 \\
2,89 \\
1,58\end{array}$ \\
\hline
\end{tabular}

ADA - Argila dispersa em água; GF - Grau de floculação; ID - Índice de dispersão = 100 - GF; ADI - Água disponível; Ucc- umidade do solo na capacidade de campo;Upmp-Umidade do solo no ponto de murchamento permanente; RAS - Relação de adsorção de sódio $=\mathrm{Na}^{+}\left[\left(\mathrm{Ca}^{+}+\mathrm{Mg}^{+}\right)\right.$] 2 $]^{1 / 2} ; \mathrm{PST}$ - Percentagem de sódio trocável $=-100\left(\mathrm{Na}^{+} / \mathrm{CTC}\right) ;{ }^{*}=0$ Obtido do complexo sortivo; $\mathrm{CTC}=$ Capacidade de troca catiônica $\left[\mathrm{Ca}^{2+}+\mathrm{Mg}^{2+}+\mathrm{K}^{+}+\mathrm{Na}^{+}+\left(\mathrm{H}^{+}+\mathrm{Al}^{3+}\right)\right]$

Tabela 2. Características químicas do biofertilizante bovino líquido e da água utilizada na irrigação

\begin{tabular}{lcc}
\hline Variáveis & Biofertilizante & Água \\
$\mathrm{pH}$ & 6,77 & 7,16 \\
$\mathrm{CE} \mathrm{a} 25^{\circ} \mathrm{C}\left(\mathrm{dS} \mathrm{m} \mathrm{m}^{-1}\right)$ & 3,11 & 0,35 \\
$\mathrm{Ca}^{2+}\left(\mathrm{mmol}_{\mathrm{c}} \mathrm{L}^{-1}\right)$ & 8,22 & 1,25 \\
$\mathrm{Mg}^{2+}\left(\mathrm{mmol}_{\mathrm{C}} \mathrm{L}^{-1}\right)$ & 11,15 & 1,23 \\
$\mathrm{Na}^{+}\left(\mathrm{mmol}_{\mathrm{C}} \mathrm{L}^{-1}\right)$ & 4,21 & 0,78 \\
$\mathrm{~K}^{+}\left(\mathrm{mmol}_{\mathrm{c}} \mathrm{L}^{-1}\right)$ & 7,48 & 0,16 \\
$\mathrm{Cl}^{-}\left(\mathrm{mmol}_{\mathrm{C}} \mathrm{L}^{-1}\right)$ & 8,50 & 2,25 \\
$\mathrm{CO}_{3}^{2-}\left(\mathrm{mmol}_{\mathrm{c}} \mathrm{L}^{-1}\right)$ & - & - \\
$\mathrm{HCO}_{3}^{-}\left(\mathrm{mmol}_{\mathrm{c}} \mathrm{L}^{-1}\right)$ & 2,34 & 0,86 \\
$\mathrm{SO}_{4}^{2-}\left(\mathrm{mmol}_{\mathrm{C}} \mathrm{L}^{-1}\right)$ & 19,87 & 0,43 \\
$\mathrm{RAS}^{-}\left(\mathrm{mmol}^{-1}\right)^{1 / 2}$ & 1,35 & 0,70 \\
\hline $\mathrm{CE}$ - condutividade elétrica; RAS - Relação de adsorção de sódio $=\mathrm{Na}^{+}\left[\left(\mathrm{Ca}^{2+}+\mathrm{Mg}^{2+}\right) / 2\right]^{1 / 2}$
\end{tabular}

Cada unidade experimental correspondeu a uma bolsa de polietileno preto com altura de 22 e diâmetro de $14 \mathrm{~cm}$, com capacidade para $3,4 \mathrm{~L}$, sendo acondicionados $3 \mathrm{~L}$ de material de solo deixando espaço suficiente para aplicação dos $300 \mathrm{~mL}$ de biofertilizante líquido. Em cada repetição foram semeadas sete sementes de nim com viabilidade de $86 \%$ obtidas em plantas de pé franco; aos 30 dias após a semeadura realizou-se o desbaste mantendo-se a mais vigorosa por bolsa plástica.

A irrigação foi feita pelo processo de pesagem utilizando-se a média das três repetições de cada tratamento para fornecer 0 volume da água evapotranspirada nas últimas $24 \mathrm{~h}$.

A avaliação da cultura foi feita aos 86 dias após a semeadura, obtendo-se os valores da altura de plantas medidos do colo ao ápice e comprimento da raiz principal, do colo ao final, por meio de régua graduada. O diâmetro do caule, rente ao solo, e da raiz principal, a $1 \mathrm{~cm}$ abaixo do colo, com auxílio de um paquímetro digital de 6" DC-60 Western aferido em milímetro, número de folhas por contagem e a massa seca total (massa seca da raiz + massa seca da parte aérea) obtida em balança analítica.

Para avaliação dos dados utilizou-se o programa computacional Sistema para Análise de Variância - SISVAR (versão 4.1), sendo o nível de significância determinado pelo teste "F" e as média comparadas pelo teste de Tukey a 0,05 de probabilidade (Ferreira, 2000).

\section{RESULTADOS E DISCUSSÃO}

Exceto sobre a condição salina do substrato (CEes) ao final do experimento, que foi influenciada pela ação isolada da salinidade das águas de irrigação e ao crescimento das plantas em altura pela salinidade das águas e pelo biofertilizante, a interação salinidade da água $\mathrm{x}$ biofertilizante exerceu efeitos significativos sobre as demais variáveis (Tabela 3).

Independente da aplicação do biofertilizante bovino, o aumento da salinidade das águas elevou linearmente a condutividade elétrica do extrato de saturação do solo, de 2,1 para até $10,4 \mathrm{dS} \mathrm{m}^{-1}$, quando irrigado com águas de $0,5,1,2,3 \mathrm{e} 4$ $\mathrm{dS} \mathrm{m}{ }^{-1}$ (Figura 1). Ao considerar que inicialmente o solo possuía condutividade elétrica de $0,78 \mathrm{dS} \mathrm{m}^{-1}$ (Tabela 1) constata-se que a irrigação, até mesmo com águas sem riscos para a agricultura (Ayers \& Westcot, 1999; Mori et al., 2011) pode elevar o caráter salino do solo. Após relacionar os valores da condutividade elétrica do extrato de saturação do solo, de 10,4 com 2,1 (dS m $\left.{ }^{-1}\right)$ percebe-se que a irrigação com a água de maior condutividade elétrica $\left(4,0 \mathrm{dS} \mathrm{m}^{-1}\right)$ elevou a condição salina do solo em 395,2\% a mais que a água não salina $\left(0,5 \mathrm{dS} \mathrm{m}^{-1}\right)$.

Pelos resultados e conforme Richards (1954) a irrigação com água de nível salino a partir de $2 \mathrm{dS} \mathrm{m}^{-1}$ transporta sais ao solo a ponto de elevar o grau de salinidade para moderadamente

Tabela 3. Resumo das análises de variância pelo quadrado médio, referente à condutividade elétrica do extrato de saturação do solo - CEes, altura de plantas - AP, diâmetro do caule - $D C$ e número de folhas - NF, diâmetro das raízes $D R$, comprimento de raiz - CR, massa seca da parte aérea - MSPA e das raízes - MSR

\begin{tabular}{lccccccccc}
\hline Fonte de variação & GL & CEes & AP & DC & NF & DR & CR & MSPA & MSR \\
Águas salinas (A) & 4 & $156,338^{* *}$ & $93,739^{*}$ & $3,537 * *$ & $70,275^{* *}$ & $3,626^{* *}$ & $218,642^{* *}$ & $16,907 * *$ & $5,606 * *$ \\
Biofertilizante (B) & 1 & $0,413 \mathrm{~ns}$ & $2316,331^{* *}$ & $28,304^{* *}$ & $209,066^{* *}$ & $35,882^{* *}$ & $1338,592^{* *}$ & $81,341^{* *}$ & $14,132^{* *}$ \\
Interação A x B & 4 & $5,902 \mathrm{~ns}$ & 58,034 ns & $0,762^{* *}$ & $7,858^{* *}$ & $2,137^{* *}$ & $198,861^{* *}$ & $1,812^{* *}$ & $0,441^{* *}$ \\
Resíduo & 50 & 2,461 & 26,821 & 0,156 & 2,526 & 0,229 & 25,421 & 0,291 & 0,113 \\
Total & 59 & - & - & - & - & - & - & - & - \\
\hline CV (\%) & & 23,31 & 18,25 & 8,95 & 13,2 & 9,96 & 19,92 & 17,9 & 25,59 \\
\hline
\end{tabular}




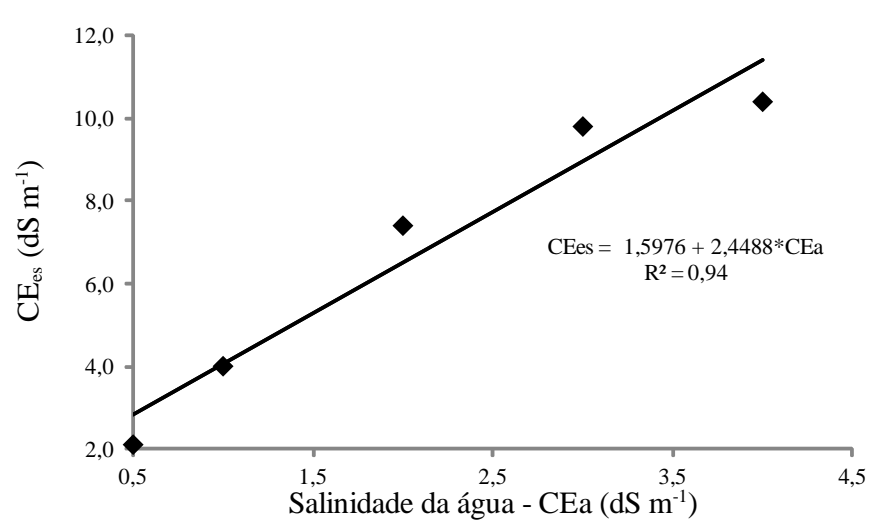

Figura 1. Valores médios da condutividade elétrica do extrato de saturação do solo $\left(\mathrm{CE}_{\mathrm{es}}\right)$ irrigado com águas salinas

salino $\left(8>\right.$ CEes $\left.>4 \mathrm{dS} \mathrm{m}^{-1}\right)$ e fortemente salino $(16>$ CEes $>8$ $\mathrm{dS} \mathrm{m}{ }^{-1}$ ). Esses incrementos podem comprometer a formação de mudas e o crescimento das plantas moderadamente sensíveis e moderadamente tolerantes (Ayers \& Westcot, 1999). Quanto ao nim, há conflitos de informações na literatura referentes ao seu comportamento em meio salino; para Freire et al. (2010) ele se comporta como moderadamente sensível e, para Silva et al. (2010) como moderadamente tolerante, em solos moderadamente e fortemente salinos de condutividade elétrica do extrato de saturação de 10,45 e $11 \mathrm{dS} \mathrm{m}^{-1}$ respectivamente.

Apesar da interação salinidade da água x biofertilizante não exercer efeitos significativos, o crescimento das plantas em altura (Tabela 1) respondeu à ação isolada dos níveis de salinidade das águas e do biofertilizante bovino (Figura 2). A irrigação com água de até $1,04 \mathrm{dS} \mathrm{m}{ }^{-1}$ não inibiu o crescimento das plantas em altura atingindo o maior valor estimado de 30,1 $\mathrm{cm}$ aos 86 dias após a emergência (Figura 2A). Por outro lado, a irrigação com águas de salinidade acima deste valor, adiciona sais ao solo em nível não tolerável pelo nim, resultando na inibição do crescimento e na perda de qualidade das mudas. Situações semelhantes foram apresentadas por Gurumurthy et al. (2007) e Freire et al. (2010) mas em níveis salinos mais elevados, após constatarem baixos índices de sobrevivência e perdas da integridade das folhas do nim quando irrigado com águas concentradas em cloreto de sódio, em níveis de 4,5 $\mathrm{dS} \mathrm{m}^{-1} \mathrm{e}$ superiores.

A adição do biofertilizante bovino promoveu maior crescimento em altura das plantas, uma vez que os valores aumentaram de 22,1 para 34,6 cm, com superioridade de 56,6\%, em comparação com as dos tratamentos sem o insumo orgânico (Figura 2B). Tendências semelhantes obtiveram Silva et al. (2008) e Nunes et al. (2009) ao obter maior crescimento de plantas de goiabeira (Psidium guajava) e noni (Morinda citrifolia) sob irrigação com águas salinas em substratos com esterco de bovino e biofertilizante bovino.

Pelos resultados, o biofertilizante mitiga a ação inibidora dos sais durante o crescimento inicial do nim. Os efeitos positivos são oriundos das substâncias húmicas, contidas no insumo, que contribuem para a melhoria física do solo, redução do potencial osmótico no interior das raízes, estimulando a absorção de água e nutrientes em meios adversamente salinos (Liang et al., 2005). Essas condições proporcionam estímulo ao

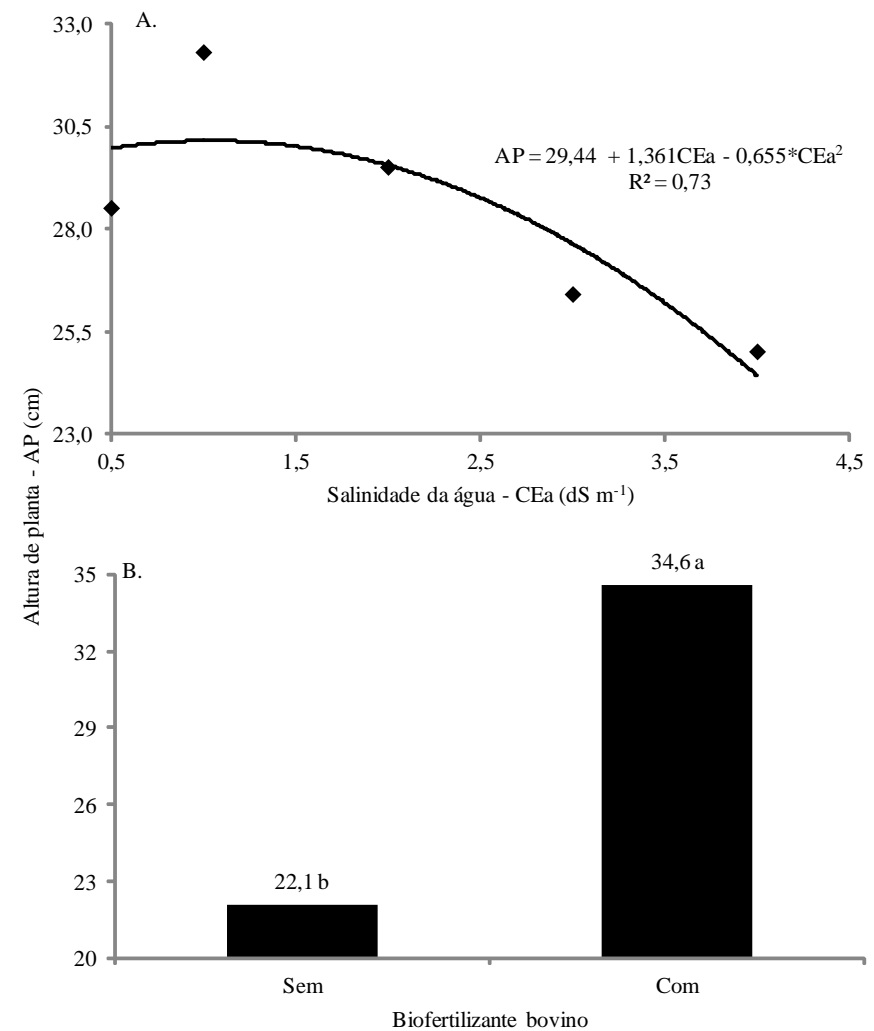

Figura 2. Altura de plantas de nim irrigado com águas salinas (A) no solo sem e com biofertilizante bovino (B)

crescimento radicular que se reflete também no crescimento da parte aérea das plantas (Silva Júnior et al., 2009).

O aumento da salinidade das águas inibiu o crescimento das plantas avaliado pelo diâmetro caulinar em ambos os substratos, porém, com efeito menos pronunciado no solo com biofertilizante bovino. Nas plantas dos tratamentos sem biofertilizante o aumento da salinidade das águas inibiu linearmente o diâmetro do caule em $0,502 \mathrm{~mm}$ por cada aumento unitário da condutividade elétrica da água de irrigação (Figura 3).

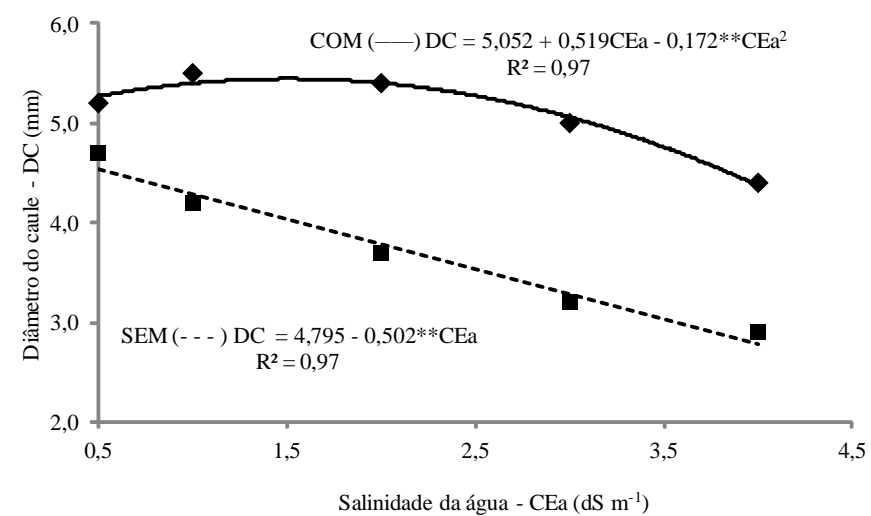

Figura 3. Diâmetro caulinar de plantas de nim irrigado com águas salinas, no solo sem (-) e com (--) biofertilizante bovino

O declínio foi de 4,8 para 2,8 mm entre os diâmetros das plantas irrigadas com a água de menor e a de maior teor salino, resultando numa redução de $41,6 \%$ em comparação com as plantas tratadas com água de $0,5 \mathrm{dS} \mathrm{m}^{-1}$. Comportamento 
semelhante foi obtido por Cha-Um \& Kirdmanee (2008) após constatarem inibição do crescimento do nim indiano sob condições salinas do solo e da água de irrigação.

A partir desses resultados, verifica-se que durante o crescimento inicial o nim não tolera ser irrigado com águas de condutividade elétrica superior a $0,5 \mathrm{dS} \mathrm{m}^{-1}$ sem perdas de qualidade das mudas. Esta situação indica comprometimento dos seus processos fisiológicos e metabólicos para a planta se ajustar e produzir substâncias vitais, como proteínas, enzimas, ácidos nucleicos e outros assimilados orgânicos como carboidratos e açúcares, indispensáveis ao seu ajustamento osmótico, crescimento e produção (Lacerda et al., 2003; Heidari, 2009).

Nos tratamentos com biofertilizante o diâmetro do caule foi significativamente superior em relação ao solo sem o insumo orgânico para qualquer nível de salinidade das águas. Constatase, também, que as diferenças entre os valores das plantas irrigadas com águas de 2, $3 \mathrm{e} 4 \mathrm{dS} \mathrm{m}^{-1}$ superam as das plantas tratadas com águas de 0,5 e $1 \mathrm{dS} \mathrm{m}^{-1}$. Apesar da superioridade o diâmetro do caule das mudas dos substratos com biofertilizante aumentou com a salinidade da água de até 1,51 $\mathrm{dS} \mathrm{m}{ }^{-1}$ atingindo o valor máximo estimado de 5,45 mm. Entretanto, ao considerar que no solo sem biofertilizante as plantas sofreram inibição do diâmetro caulinar a partir da salinidade da água de $0,5 \mathrm{dS} \mathrm{m}^{-1}$, verifica-se que a aplicação do insumo orgânico atenuou os efeitos negativos da salinidade e estimulou o crescimento das plantas em meio salino. Esses resultados estão em acordo com Asik et al. (2009) ao concluírem que o húmus e o ácido húmico reduziram os efeitos danosos do cloreto de sódio, aos níveis de 0, 15, 30 e $60 \mathrm{mM}$, no crescimento e produção de trigo.

Comparativamente, o nim comportou-se de forma semelhante ao noni (Nunes et al., 2009) em que, apesar do diâmetro do caule das plantas ser inibido com o aumento da salinidade das águas de irrigação, os resultados foram sempre superiores nos tratamentos com biofertilizante, situação esta compatível com a registrada para o crescimento em altura (Figura 2) em que o insumo inibiu a ação depressiva dos sais com supremacia dos valores nas plantas desenvolvidas no solo com o insumo orgânico.

O aumento da salinidade das águas de irrigação inibiu a emissão das folhas nos tratamentos sem e com biofertilizante bovino mas, como registrado para o diâmetro caulinar, sempre em menor proporção nas plantas dos tratamentos com o insumo orgânico (Figura 4). Apesar da superioridade em relação aos tratamentos sem o insumo, o aumento do teor salino das águas resultou em perdas de emissão foliar de 1,008 folha para cada incremento unitário da condutividade elétrica das águas.

Nas plantas dos tratamentos sem biofertilizante os valores foram reduzidos de 13,7 para 7,0 folhas planta $^{-1}$, com perdas de até $49 \%$ entre os números de folhas emitidas pelas plantas irrigadas com a água de menor e de maior salinidade. O aumento do estresse salino da água ou do solo inibe a emissão das folhas. Esta inibição se torna mais prejudicial quando resulta em menor comprimento e largura reduzindo a expansão foliar, com reflexos negativos na taxa de fotossíntese líquida prejudicando os processos fisiológicos e bioquímicos das plantas em geral, inclusive em nim indiano como constatado por Cha - Um \& Kirdmanne (2008). As reduções são

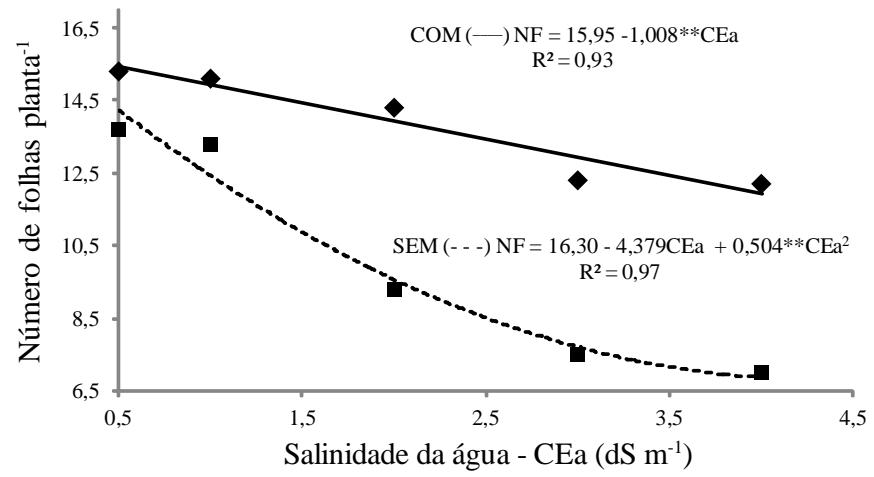

Figura 4. Número de folhas por planta de nim sob irrigação com águas salinas, no solo sem (-) e com (--) biofertilizante bovino

semelhantes às obtidas por Sousa et al. (2008) e Rebequi et al. (2009) durante a formação de mudas do maracujazeiro amarelo e de limão cravo (Citrus limonia) sob irrigação com águas salinas, com menores declínios nas plantas dos tratamentos com biofertilizante bovino.

Como no crescimento em altura, diâmetro do caule e número de folhas, o bifertilizante promoveu condições no solo para o maior crescimento avaliado pelo diâmetro e comprimento da raiz principal das plantas (Figura 5). Enquanto o diâmetro das raízes principais a $1 \mathrm{~cm}$ abaixo do colo decresceu com o aumento da salinidade das águas nos tratamentos sem biofertilizante, a adição do insumo estimulou o desenvolvimento radicular nas plantas irrigadas com água de condutividade elétrica, máxima
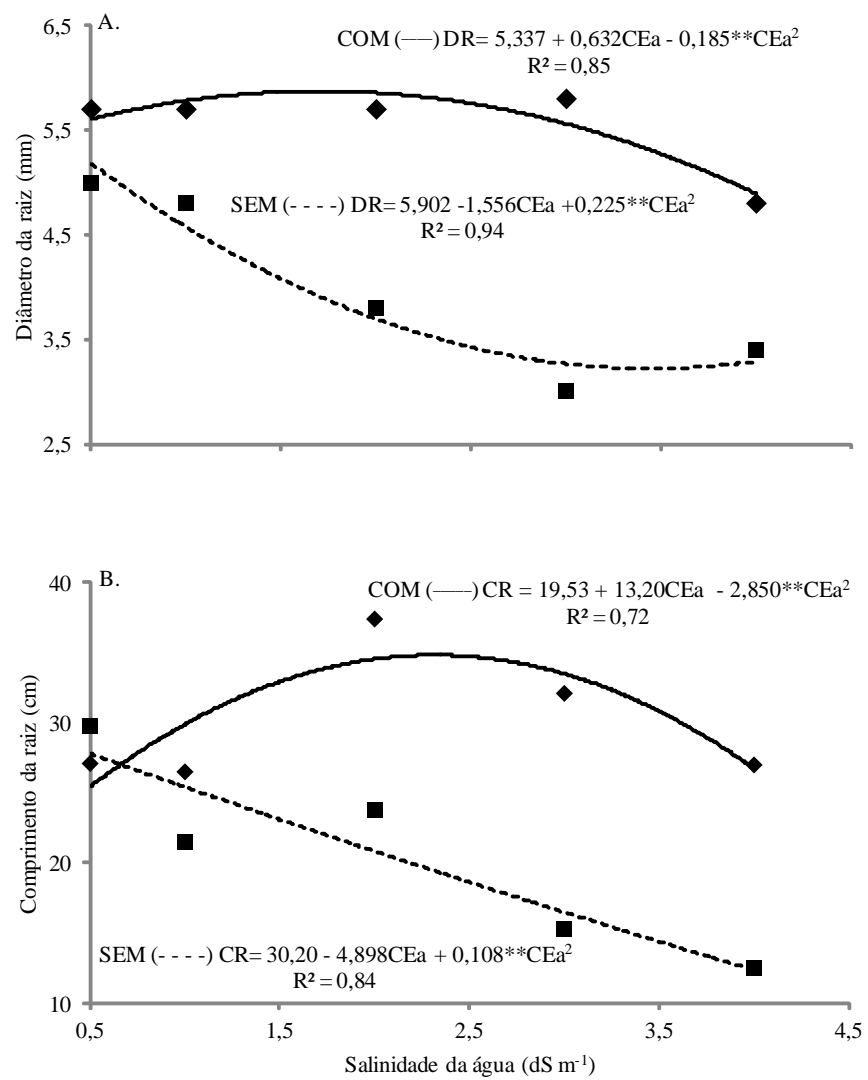

Figura 5. Diâmetro (A) e comprimento da raiz principal (B) do nim irrigado com águas salinas, no solo sem (- - -) e com (----) biofertilizante bovino 
estimada, de até $1,7 \mathrm{dS} \mathrm{m}{ }^{-1}$ atingindo o maior valor estimado de $5,87 \mathrm{~mm}$ (Figura 5A). Quanto ao comprimento (Figura 5B) as raízes principais cresceram até o valor máximo estimado de $34,81 \mathrm{~cm}$ na salinidade máxima estimada da água de $2,3 \mathrm{dS} \mathrm{m}^{-1}$.

A irrigação com águas de condutividade elétrica acima dos respectivos valores máximos estimados estressou as plantas e inibiu o diâmetro e o crescimento das raízes, comprometendo a qualidade das mudas. Percebe-se, nas plantas irrigadas com a água de maior salinidade $\left(4 \mathrm{dS} \mathrm{m}^{-1}\right)$, nos tratamentos sem e com biofertilizante, valores de 3,4 e $5 \mathrm{~mm}$ para o diâmetro e de 12,5 e 29,8 cm para o comprimento das raízes com superioridades de 47 e $138 \%$ nas plantas tratadas com o insumo orgânico. Os declínios nas plantas dos tratamentos sem biofertilizante são provocados pelas perdas de turgescência das células, redução das atividades metabólicas e trocas gasosas das plantas, sob estresse salino (Silva et al., 2011).

Como em todas as variáveis, o aumento da condutividade elétrica das águas comprometeu mais a produção de biomassa seca das raízes e parte aérea das plantas nos tratamentos sem biofertilizante (Figura 6). Os insumos orgânicos, inclusive o biofertilizante bovino na forma líquida, promovem a melhoria físico-hídrica do substrato resultando em maior espaço poroso (Mellek et al., 2010) para o crescimento radicular; promovem também, redução do potencial osmótico entre o interior das raízes e a solução do solo possibilitando ajustamento das plantas à salinidade devido à melhoria na eficiência fotossintética e trocas gasosas das plantas cultivadas em ambiente salino (Asik et al., 2009; Silva et al., 2011). Apesar da
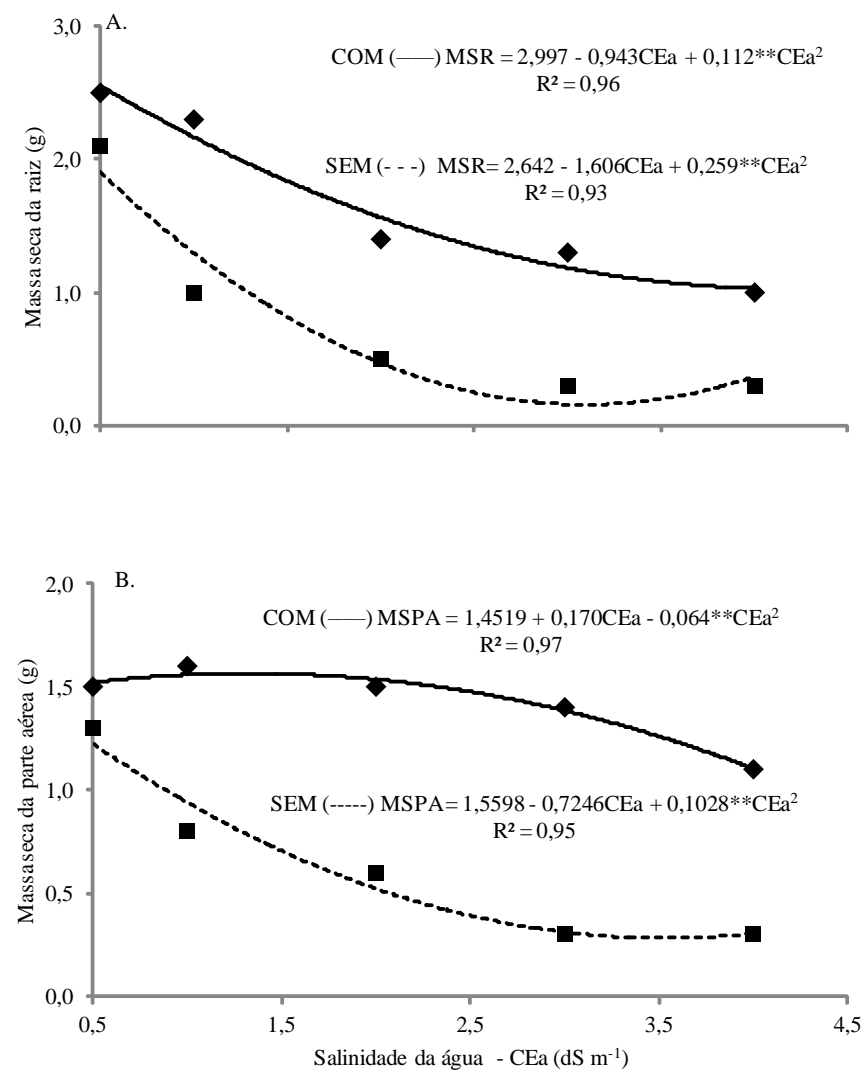

Figura 6. Massa seca das raízes (A) e da parte aérea (B) das plantas irrigadas com águas salinas, no solo sem (- - -)e com (----) biofertilizante bovino superioridade da biomassa seca das raízes nos tratamentos com biofertilizante (Figura 6A) em relação à parte aérea (Figura 6B), a irrigação com água de condutividade elétrica superior a $0,5 \mathrm{dS} \mathrm{m}^{-1}$ prejudicou a produção de biomassa radicular do nim situação que indica, como verificado nas demais variáveis, que mesmo com a supremacia dos valores nos tratamentos com o insumo orgânico o biofertilizante ameniza mas não elimina os efeitos degenerativos da salinidade da água e do solo às plantas de nim.

\section{CONCLUSÕES}

1. O biofertilizante bovino inibiu os efeitos depressivos da salinidade da água às mudas de nim em relação ao substrato sem o insumo orgânico.

2. O biofertilizante possibilita o uso de águas com salinidade de 1,04, 1,51, 1,70 dS m ${ }^{-1}$ sem inibição do crescimento em altura, diâmetro caulinar e diâmetro das raízes principais do nim, que foram comprometidas com água de salinidade acima de 0,5 $\mathrm{dS} \mathrm{m} \mathrm{m}^{-1}$, no tratamento sem o respectivo insumo.

\section{LITERATURA CITADA}

Asik, B. B., Turan, M. A.; Celik, H.; Katkat, A. V. Effects of humic substances on plant growth and mineral nutrients uptake of wheat (Triticum durum cv. Salihli) under conditions of salinity. Asian Journal of Crop Science, v.1, p.87-95, 2009.

Ayers, R. S.; Westcot, D. W. A qualidade da água na agricultura. Campina Grande: UFPB, 1999. 153p. Estudos FAO: Irrigação e Drenagem, 29

Azevedo, A. I. B.; Lira, A. S.; Cunha, L. C.; Almeida, F. de A. C.; Almeida, R. P. Bioatividade do óleo de nim sobre Alphitobius diaperinus (Coleoptera: Tenebrionidae) em sementes de amendoim. Revista Brasileira de Engenharia Agrícola e Ambiental, v.14, p.309-313, 2010.

Chaturvedi, R.; Razdan, M. K.; Bhojwani, S. S. In vitro morphogenesis in zygotic embryo cultures of neem (Azadirachta indica A. Juss.). Plant Cell Reports, v.22, p.801809, 2004.

Cha-Um, S.; Kirdmanee, C. Assessment of salt tolerance in eucalyptus, rain tree and thai neem under laboratory and the field conditions. Pakistan Journal Botany, v.40, p.20412051, 2008.

EMBRAPA - Empresa Brasileira de Pesquisa Agropecuária. Centro Nacional de Pesquisas de Solos. Manual de métodos de solo. 2.ed., Rio de Janeiro: Embrapa CNPS, 1997. 212p. Documentos, 1

Ferreira, D. F. Sistema de análises de variância para dados balanceados. Lavras: UFLA, 2000. SISVAR 4.1

Freire, A. L. O.; Sousa Filho, G. M.; Miranda, J. R. P.; Souto, P. C. S.; Araújo, L. V. C. Crescimento e nutrição mineral do nim (Azadirachta indica A. Juss.) e cinamomo (Melia azedarach linn.) submetidos à salinidade. Ciência Florestal, v.20, p.207215, 2010. 
Gurumurthy, B. R.; Nataraju, S. P.; Rudramurthy, H. V.; Shivanna, M. B. Influence of soil salinity on relative biomass and critical limits of growth in selected tree species. Karnataka Journal Agriculture Science, v.20, p.133-134, 2007.

Heidari, M. Variation in seed germination, seedling growth, nucleic acid and biochemical component in canola (Brassica nupus L.) under salinity stress. Asian Jouranl of Plant Science, v.8, p.557-561, 2009.

Lacerda, C. F. de; Cabraia, J.; Cano, A. O.; Ruiz, H. A.; Prisco, J. T. Solute accumulation and distribution during shoot and leaf development in two sorghum genotypes under salt stress. Environmental and Experimental Botany, v.49, p.107-120, 2003.

Liang, Y. C.; Si, J.; Nikolic, M.; Peng, Y.; Cheng, W.; Jiang, Y. Organic manure stimulates biological activity barley growth in soil subject to secondary salinization. Soil Biology and Biochemistry, v.37, p.1185-1195, 2005.

Medeiros, J. F. de; Nascimento, I. B.; Gheyi, H. R. Manejo do solo-água-planta em áreas afetadas por sais. In: Gheyi, $\mathrm{H}$. R; Dias, N. S; Lacerda, C. F. de (ed) Manejo da salinidade na agricultura: Estudos básicos e aplicado. 1 ed. Fortaleza: Instituto Nacional de Ciência e Tecnologia em Salinidade, 2010, cap. 16, p.279-302.

Mellek, J. E.; Dieckow, J.; Silva, V. L.; Favaretto, N.; Pauletti, V.; Vezzani, F. M.; Souza, J. L. M. Dairy liquid manure and notillage: Physical and hydraulic properties and carbon stocks in a Cambisol of Southern Brazil. Soil \& Tillage Research, v.110, p.69-76, 2010.

Mori, M.; Di Mola, I.; Chiaranda, F. Q. Salt stress and transplant time in snap been: Growth and productive behavior. International Journal of Plant Production, v.5, p.49-64, 2011.

Mourão, S. A.; Silva, J. C. T.; Guedes, R. N. C.; Venzon, M.; Jham, G. N.; Oliveira, C. L.; Zanuncio, J. C. Seletividade de extratos de nim (Azadirachta indica A. Juss.) ao ácaro predador Iphiseiodes zuluagai Denmark Muma (Acari: Phytoseiidae). Neotropical Entomology, v.33, p.613-617, 2004.

Neves, E. J. M. Importância dos fatores edafo-climáticos para o uso do Nim (Azadirachta indica A. Juss) em programas florestais e agroflorestais nas diferentes regiões do Brasil. Colombo: Embrapa Florestas, 2004, p.99-107. Boletim de Pesquisa Florestal, n. 49
Nunes, J. C.; Cavalcante, L. F.; Rebequi, A. M.; Lima Neto, A. J.; Diniz, A. A; Silva, J. J. M.; Brehm, M. A. S. Formação de mudas de noni sob irrigação com águas salinas e biofertilizante bovino no solo. Engenharia Ambiental, v 6, p.451-463, 2009.

Rebequi, A. M.; Cavalcante, L. F.; Nunes, J. C.; Diniz, A. A.; Brehm, M. A. S.; Cavalcante, M. Z. B. Produção de mudas de limão cravo em substrato com biofertilizante bovino irrigado com águas salinas. Revista de Ciências Agrárias, v.32, p.219-228, 2009.

Richards, L. A. Diagnostico y rehabilitación de suelos salinos y sódicos. México: Departamento de Agricultura de los Estados Unidos de América, 1954. 174p. Handbook, 60

Silva, E. C.; Nogueira, R. J. M. C.; Araújo, F. P.; Melo N. F.; Azevedo Neto, A. D. Physiological responses to salt stress in young umbu plants. Enviromental and Experimental Botany, v.63, p.147-157, 2008.

Silva, F. L. B.; Lacerda, C. F. de; Sousa, G. G.; Neves, A. L. R.; Silva, G. L.; Sousa, C. H. C. Interação entre salinidade e biofertilizante bovino na cultura do feijão-de-corda. Revista Brasileira de Engenharia Agrícola e Ambiental, v.15, p.383389, 2011.

Silva Júnior, Tavares, R. C. Mendes Filho, Gomes, V. F. F. Efeitos de níveis de salinidade sobre a atividade microbiana de um Argissolo Amarelo incubado com diferentes adubos orgânicos. Revista Brasileira de Ciências Agrárias, v.4, p.378382, 2009.

Silva, R. M.; Masutti, C. S. M.; Silva, J. A. B. Desenvolvimento inicial de juazeiro (Ziziphus joazeiro) e nim (Azadirachta indica) em solos afetados por sais no município de Juazeiro/ BA. In: Simpósio Brasileiro de Salinidade, 1, 2010. Fortaleza. Anais...Fortaleza: INCTSal, 2010. CD Rom

Sousa, G. B.; Cavalcante, L. F.; Cavalcante, I. H. L.; BekmannCavalcante, M. Z.; Nascimento, J. A. Salinidade do substrato contendo biofertilizante para formação de mudas de maracujazeiro amarelo irrigado com água salina. Revista Caatinga, v.21, p.172-180, 2008. 